\title{
ELUCUBRACIONES ACERCA DEL DERECHO FUNDAMENTAL AL OLVIDO EN EL PERÚ Y EN EL DERECHO COMPARADO, A PROPÓSITO DE SU RECONOCIMIENTO Y EVOLUCIÓN ${ }^{1}$
}

\author{
Jorge Isaac Torres Manrique ${ }^{2}$ \\ Docente Principal en Worldwide Legal Consulting de la California Silicon Valley School of the Law, SFO
}

(Recibido: Mayo, 2017/ Aceptado: Diciembre, 2017)

\section{Resumen}

El derecho fundamental al olvido, es un nuevo derecho que surge como resultante negativo del desarrollo de la tecnología. Así, el derecho al olvido se encuentra orientado a impedir y contrarrestar los perjuicios que genera la no poca como dañina información personal publicada en la Red. En la presente entrega, el autor analiza de manera profunda como amplia, los diversos alcances y aristas del mismo, para concluir esbozando propuestas al respecto.

Palabras Claves: Derecho fundamental al olvido, derecho al olvido digital, derecho a la caducidad del dato negativo, derecho a la oscuridad digital, derecho a desindexar.

\begin{abstract}
The fundamental right to forget, is a new right that arises as a negative result of the development of technology. Thus, the right to oblivion is aimed at preventing and counteracting the damages caused by the no little as harmful personal information published on the Net. In the present presentation, the author analyzes in a profound manner how wide, the various reaches and edges of the same, to conclude sketching proposals on the matter.
\end{abstract}

Keywords: right to be forgotten, right to digital oblivion, right to expiration of the negative data, right to be forgotten, right to digital darkness.

\footnotetext{
${ }^{1}$ El autor dedica el presente trabajo al ilustrísimo jurista, Prof. Dr. Dr. h.c. mult. Robert Alexy. Cabe precisar, que, en homenaje al mismo, se llevó a cabo la I Convención Mundial de Derechos Fundamentales y Garantías Constitucionales, en la ciudad de Lima, los días 06 y 07/12/16. Magno evento en el cual, tuvo el gran honor de haber sido invitado para ser ponente y cuya temática de dicha oportunidad, aborda la presente entrega en versión completa.

${ }^{2}$ Autor para correspondencia. Email: kimblellmen@outlook.com.
} 


\section{Introducción}

El desarrollo de la humanidad comporta avances en las diversas áreas del saber, ello genera el advenimiento de nuevos escenarios de ineludible interactuar. Si bien es cierto que estos avances son mayormente en beneficio de la humanidad, ello no es óbice para que se configure también, inconvenientes, situaciones no deseables, perjudiciales.

Así, el Derecho fiel a su naturaleza de ser sombra que sigue a la realidad para hacer posible la convivencia del ser humano en sociedad, advierte situaciones acontecidas en y cómo producto de la cada vez más masificada utilización de la Internet. Un ejemplo de lo anterior, es la problemática que sobreviene a los efectos del incorrecto tratamiento de la información personal contenida en ella. En ese sentido, resulta pertinente citar lo dicho por RALLO LOMBARTE, que "el carácter global y universal de la Red, así como el hecho de la permanencia y fácil acceso de la información contenida en ella, ponen de relieve la necesidad de que, de una parte, los usuarios tomen conciencia de las informaciones propias y de terceros- que suministran, con el fin de evitar una posible pérdida de control de las mismas cuando se incorporen en Internet; $y$ de otra, que se dote a al usuario de mecanismos efectivos de defensa ante los riesgos que pueda entrañar el imparable desarrollo de este sistema" (2010, pág. 1). Y es que, como es lógico y no se pudo prever en su momento, ciertamente no poca información personal on line, se encuentra revestida de una fecha de expiración.

Así, en palabras del mismo autor, es de mencionar que, mientras que fuera de la Red, el ciudadano otorga sus datos para una finalidad concreta y existe la posibilidad de que éstos se cancelen una vez agotada su finalidad, en Internet existen los motores de búsqueda, que dotan de un carácter cuasi eterno que puede alterar la línea del tiempo (Rallo Lombarte, 2010, pág. 2).

En la presente entrega, los invitamos pues, a acompañarnos a este recorrido fascinante de reflexiones y óptica critica, a lo relacionado al derecho fundamental al olvido.

\section{Antecedentes}

El antecedente en strictu sensu del derecho fundamental al olvido es el derecho a la protección de datos personales o el derecho a la autodeterminación informativa, conocido también como derecho a la protección de datos de carácter personal. Empero, se debe tener en cuenta que el segundo derecho nombrado (a diferencia del derecho al olvido), se encuentra referido a información que no se encuentre registrada en la Red.

Sin embargo, por otro lado, es sabido que, el derecho fundamental al olvido es reconocido de manera primigenia, en sede jurisprudencial por el Tribunal de Justicia de la Unión Europea, también conocido como Tribunal de Luxemburgo (debido a la ubicación de su sede). Al respecto en términos de HERNÁNDEZ (2016), es de señalar el derecho al olvido en Internet es una creación del Tribunal de Justicia de la Unión Europea, aunque sería más propio hablar de un reconocimiento del derecho por parte del Tribunal antes que una creación jurisprudencial del mismo. 
Sin embargo, la Federación Internacional de Asociaciones de Bibliotecarios y Bibliotecas de los Países Bajos (pág. 1) sostiene que "el concepto de eliminar enlaces con determinados contenidos de resultados de búsquedas en Internet no es completamente nuevo(...)aún antes de la sentencia de 2014 del Tribunal de Justicia de la Unión Europea descripto a continuación, Google aceptó solicitudes para eliminar enlaces en todos sus sitios web de aquellos resultados de búsquedas que comprometieran la seguridad financiera o cierta información personal, como por ejemplo enlaces hacia obras protegidas por el derecho de autor, números de seguridad social, información bancaria personal y firmas. Dicho esto, desde la sentencia europea de 2014 se han dictado sentencias y se han presentado propuestas legislativas en países de todo el mundo que aplican de manera explícita alguna versión del concepto de 'derecho al olvido'. Esta tendencia tiene su origen en la legislación europea sobre 'procesamiento de datos' de la década del noventa y en otros conceptos antiguos previos a Internet".

La indicada Federación Internacional, hace un repaso de lo acontecido en algunos países, lo que resumiremos brevemente:

i) El Art. 8 de la Carta de los Derechos Fundamentales de la Unión Europea (2000), sobre el tratamiento de los datos personales, establece: "Toda persona tiene derecho a la protección de los datos de carácter personal que le conciernan" y "dichos datos se tratarán de modo leal, para fines concretos y sobre la base del consentimiento de la persona afectada o en virtud de otro fundamento legítimo previsto por la ley".

ii) En Hong Kong: David Webb propietario de un sitio web que ofrece información sobre gestión empresarial en Hong Kong y creó un archivo de sentencias judiciales que está disponible al público y que puede consultarse ingresando el nombre de una persona. En 2010 y 2012, en un caso que involucraba a un matrimonio el Poder Judicial eliminó los nombres de ambos, y la Comisión de Privacidad de Hong Kong ordenó que Webb eliminara los nombres de estas personas de los documentos judiciales que estaban archivados en el sitio web.

iii) En Japón: El 2014 el tribunal ordenó a Yahoo Japan Inc. que eliminara los enlaces de su sitio web. 18 Siguiendo los lineamientos del caso, Yahoo Japan Inc. anunció públicamente que implementaría criterios propios para aplicar el derecho al olvido. 19 Además de estos casos, los tribunales de primera instancia de Japón pueden dictar disposiciones provisionales con respecto a solicitudes para eliminar información personal. En 2014, el tribunal de primera instancia de Tokio hizo lugar a 711 casos de demandas para eliminar información privada disponible en Internet, y ordenó que Google, Yahoo y otros proveedores eliminaran la información, tal como los demandantes habían solicitado.

iv) En México: Un hombre de negocios vinculado al transporte quería eliminar de Internet todo enlace con comentarios negativos acerca del negocio familiar, incluido el rescate financiero recibido del gobierno por un préstamo incobrable a sus empresas. En el caso Instituto Nacional de Acceso a la Información (INAI), Carlos Sánchez de la Peña vs. Google México, S. de R. L., PPD.0094/14, la Comisión dictaminó que el pedido cumplía los requisitos legales de privacidad que permitían la eliminación de la información si "la persistencia causara daños", aun cuando los artículos originales se hubieran publicado legalmente. 
De lo referido, podemos acotar que los antecedentes del derecho al olvido, no conoce fronteras o distingue países. Ello, sería correspondiente, en la medida que, hace su aparición en la Red y ésta a su vez, también se encuentra en casi todo el orbe.

\section{3. ¿Qué entendemos por derecho fundamental al olvido?}

El derecho al olvido se define de tres formas: "i) un término ficticio cuyo núcleo es el derecho a acceder, rectificar y cancelar nuestros datos personales que estén en bases ajenas; ii) obligaciones especiales de eliminación de datos financieros y penales después de cierto tiempo; iii) la desindexación de información en buscadores, es decir, que no se elimine la información, sino que simplemente deje de aparecer en el buscador" (Pérez de Acha, 2015).

La Agencia Española de Protección de Datos (AEPD) (s.f.), autoridad de control independiente que vela por el cumplimiento de la normativa sobre protección de datos y garantiza y tutela el derecho fundamental a la protección de datos personales; respecto al derecho al olvido sostiene es la manifestación de los tradicionales derechos de y cancelación y oposición aplicados a los buscadores de internet. Hace referencia al derecho a impedir la difusión de información personal a través de internet cuando su publicación no cumple los requisitos de adecuación y pertinencia previstos en la normativa. En concreto, incluye el derecho a limitar la difusión universal e indiscriminada de datos personales en los buscadores generales cuando la información es obsoleta o ya no tiene relevancia ni interés público, aunque la publicación original sea legítima (en el caso de boletines oficiales o informaciones amparadas por las libertades de expresión o de información).

De ahí que, "no hay que confundir el derecho al olvido y el derecho a la privacidad. Este último se refiere a una información que nunca se ha dado a conocer públicamente, mientras que el derecho al olvido habla de información que alguna vez fue pública y que, ahora, no debería poder recuperarse mediante rastreo. Esto se debe tener en cuenta porque fue lo que trajo algunas discusiones sobre la definición y/o límites del concepto. Aunque el derecho al olvido existe desde 2006, se empezó a aplicar a los datos en Internet el 13 de mayo de 2014, cuando la Corte Europea de Justicia ratificó que el «derecho al olvido» es un derecho humano" (Educar, 2016).

Entonces, a priori podemos colegir la naturaleza de oportunidad entre los derechos fundamentales a la privacidad y al olvido. En el primer caso, se ejercita principalmente ex ante, esto es, de manera anterior a la posible publicación de la información, a diferencia del segundo, donde siempre se manifiesta ex post, es decir, luego de haberse publicado, ya sea con el consentimiento o no del perjudicado.

Además, el derecho al olvido comporta la no republicación o redivulgación de hechos o acusaciones, aunque ciertas y ya conocidas, no resulten ser exactas o actualizadas, en razón a que ya fueron juzgados en su oportunidad y, por ende, el sancionado ya habría quedado rehabilitado, pues, no por ello, tendría que merecer una condena on line de por vida, debido a la ya consabida capacidad de Internet, de no olvido cuasi perpetuo. 
Por otro lado, imposible no referir a los derechos ARCO como fuente originaria del derecho al olvido. En esa línea, REVOREDO (2016) refiere de los mimos como una consecuencia directa de los ya conocidos derechos ARCO, los mismos que están estrechamente relacionados con las normas de protección de datos personales. Los derechos ARCO, recogidos en distintas legislaciones a nivel internacional, permiten que el titular de los datos personales en cuestión, solicite el Acceso, la Rectificación, la Cancelación u Oposición, entre otros, al tratamiento de sus datos en cualquier Banco de Datos.

$\mathrm{Y}$ es que, en principio, vale decir que desde la llegada de la Internet (International Network of Computers), conocida también como Red o Inet, todo pasó a ser publicable (y para los efectos del presente estudio, sin contar necesariamente con la aprobación del titular de la información, digamos, el internauta a quien se refiere la misma). Ello propició la indiscriminada como inconmensurable publicación de todo y por todo.

Además, sostenemos que resulta relativamente fácil obtener información por el interesado o no - ya sea, por curiosidad o seducción de ser encontrable y trascendente (por parte del internauta), o para consultar antecedentes (por parte de potenciales empleadores) - y, por consiguiente, poder advertir también la eventual vulneración al derecho al olvido del perjudicado. En términos cercanos se expresa MATE (2016, pág. 188) cuando menciona que lo que coloquialmente se denomina googlearse -incluir el nombre propio o el de otra persona en un motor de búsqueda, para comprobar qué resultados aparecen; dicha práctica recibe también el nombre de egosurfing. Así, postulamos que el derecho fundamental al olvido, proviene de un derecho más amplio, que el denominado derecho a Internet. A la vez, el derecho a la intimidad guarda estrecha relación con el derecho al olvido; existiendo entre ellos una relación de género y especie, respectivamente.

El derecho fundamental al olvido, viene recibiendo diversas denominaciones, entre ellas: derecho al olvido digital, derecho a la caducidad del dato negativo, derecho a ser olvidado, derecho a la oscuridad digital, derecho a desindexar, derecho a la supresión, derecho al olvido cibernético, derecho a la protección de datos personales on line, derecho a la desvinculados de datos.

Sin embargo, a propósito de su denominación: “derecho al olvido", considero que no resulta acertado. Ello, en vista que el olvido resulta ser propio de la psicología de las personas naturales, como medida de protección de la memoria. Sin embargo, en primer término, la Red no cuenta con vida propia, ergo no puede olvidar. Así, su definición más acertada sería: "derecho a la desindexación de datos personales". Pero, dado cuenta que la misma ("derecho al olvido"), viene siendo utilizada en casi la totalidad de Estados que lo abordan, importa poco la eventual empresa de cambio de denominación del mismo.

\section{Actores, legitimidad e implicancia de su vulneración}

En el derecho fundamental al olvido existen ineludiblemente los siguientes actores, sin la totalidad de los cuales no podría configurarse o apelarse al mismo. Así tenemos: i) Internautas, ii) Buscadores, gestores o motores de búsqueda, en línea, iii) Páginas o portales 
web, iv) Enlaces web o links, v) Información del afectado publicada en la Red, devenida en anacrónica e inexacta, y vi) El afectado.

La existencia del derecho fundamental al olvido basa su legitimación, en el derecho del afectado que le dejen vivir en paz, ya sea, por información de carácter personal que circule en internet, al margen que la misma pueda ser cierta, falsa o desactualizada.

$\mathrm{Al}$ ejercer su derecho de oposición a la referida información —esto es, conseguir que su información no sea accesible (sea desindexada, desvinculada) a través de los buscadores de la Red - el afectado, consigue también, evitar la vulneración de sus derechos al honor, a la buena reputación, al desarrollo de su libre personalidad. Se debe tomar en cuenta, que dichas vulneraciones pueden ser incluso, sistemáticas.

La vulneración del derecho al olvido, significa a su vez, el menoscabo del derecho fundamental al libre desarrollo de la personalidad del afectado. Ello, en vista a que se limita su derecho de llevar una vida alejada de limitaciones, señalamientos o estigmatizaciones que, dicho sea de paso, conlleven a la vulneración de adicionales derechos como, por ejemplo, al trabajo, a la no discriminación, al honor, a la buena reputación, entre otros.

\section{Constitucionalizado, pero no legalizado}

Resulta innegable que el derecho al olvido se encuentra reconocido de manera no expresa, esto es, bajo la naturaleza de números apertus de los derechos fundamentales reconocidos por el Art. $3^{\circ}$.-, de la Constitución Política del Perú, que preconiza: "La enumeración de los derechos establecidos en este capítulo no excluye los demás que la Constitución garantiza, ni otros de naturaleza análoga o que se fundan en la dignidad del hombre, o en los principios de soberanía del pueblo, del Estado democrático de derecho y de la forma republicana de gobierno".

Y es que, aunque suene contradictorio, es de reconocer que taxativa y reglamentariamente, el derecho fundamental al olvido no se registra de manera específica en la norma legal (salvo contadas excepciones: como Nicaragua y Rusia) (Pérez de Acha, 2015). Al respecto, preocupa que lo mencionado no solo ocurra en la región, sino también en Europa. Así, es de apostrofar el que: "(...)en lo que al derecho al olvido se refiere, en España no existe ningún reconocimiento normativo expreso al referido derecho y en otros países miembros su reconocimiento se ha visto frustrado como en Italia o no ha adquirido rango normativo como en Francia” (Mate Satué, 2016, pág. 218).

\section{Principios rectores del derecho al olvido}

Ciertamente, a la fecha, los principios jurídicos del derecho al olvido no se encuentran establecidos. Ello, en razón a que consideramos que el derecho de protección de datos personales, contiene o resulta más amplio que los alcances del derecho al olvido. Prueba de esto es que los diversos pronunciamientos de los tribunales en casos sobre el derecho al olvido, han sustentado sus decisiones en algunos de los principios jurídicos básicos de 
protección de datos personales, si llegar a precisar principios propios o exclusivos del derecho al olvido. Así, tenemos:

6.1. De Finalidad. - Según el Inc. 2., de Art. 4., de la Ley de Protección de Datos de Carácter Personal, Ley No 15/1999, se tiene que: "Los datos de carácter personal objeto de tratamiento no podrán usarse para finalidades incompatibles con aquellas para las que los datos hubieran sido recogidos. No se considerará incompatible el tratamiento posterior de éstos con fines históricos, estadísticos o científicos".

6.2. De Pertinencia. - El Inc. 5., de Art. 4., de la Ley de Protección de Datos de Carácter Personal, Ley $\mathrm{N}^{\circ}$ 15/1999, se tiene que: “Los datos de carácter personal serán cancelados cuando hayan dejado de ser necesarios o pertinentes para la finalidad para la cual hubieran sido recabados o registrados. No serán conservados en forma que permita la identificación del interesado durante un período superior al necesario para los fines en base a los cuales hubieran sido recabados o registrados (...)".

6.3. De Veracidad y Exactitud. - Al respecto, Inc. 3., de Art. 4., de la Ley de Protección de Datos de Carácter Personal, Ley No 15/1999, establece: "los datos de carácter personal serán exactos y puestos al día de forma que respondan con veracidad a la situación actual del afectado".

6.4. De Calidad.- El Art. 5., del Convenio No 108 del Consejo de Europa, para la Protección de las Personas con respecto al Tratamiento Automatizado de Datos de Carácter Personal; en referencia a la calidad de los datos Los datos de carácter personal que sean objeto de un tratamiento automatizado, respectivamente estipula: "a) Se obtendrán y tratarán leal y legítimamente; b) se registrarán para finalidades determinadas y legítimas, y no se utilizarán de una forma incompatible con dichas finalidades; c) serán adecuados, pertinentes y no excesivos en relación con las finalidades para las cuales se hayan registrado; d) serán exactos y si fuera necesario puestos al día; e) se conservarán bajo una forma que permita la identificación de las personas concernidas durante un período de tiempo que no exceda del necesario para las finalidades para las cuales se hayan registrado".

\section{Fuentes donde advertir su vulneración}

Qué duda cabe que si lo que se quiere es saber a cabalidad la existencia de una eventual información publicada que sea vulneratoria del derecho al olvido, resulta importante tener conocimiento el lugar o lugares virtuales donde poder consultar la misma. De otro modo, esto es, ante el desconocimiento o manejo incompleto de las fuentes de consulta, la defensa irrestricta de nuestro derecho al olvido se vería socavada.

En ese sentido, las fuentes de datos en línea, que pueden estar vinculadas o no a los motores de búsqueda son: i) las redes sociales, ii) los poderes públicos y iii) los medios de comunicación digitales (Mate Satué, 2016, pág. 197). 


\section{El derecho al olvido en la jurisprudencia}

El hecho que la legislación no refiera aun al reconocimiento al derecho al olvido, ello no implica que los tribunales no puedan desconocer el derecho a la tutela procesal efectiva correspondiente. En ese sentido, resulta imperante exponer brevemente algunos casos del orbe, que datan al respecto. Señala DE VERDA Y BEAMONTE (2014) que "en la jurisprudencia italiana es muy conocido el caso resuelto por la Ordenanza del Juzgado Roma de 6 de mayo 1983 (FI 1984, I, 299), que prohibió cautelarmente la difusión en televisión de una película-documental, sobre la muerte, una tarde de 1977, del famoso jugador de fútbol del "Lazio", Lucciano Re Cecconi. El deportista, queriendo gastar una broma a un amigo joyero, al que habían atracado varias veces, en compañía de otras personas, fue a su tienda y, cuando estaba de espaldas, le gritó: "Esto es un atraco", a lo que éste respondió, volviéndose y disparándole un tiro que acabó con su vida, sin tener tiempo de reconocerlo. El joyero fue acusado por el Ministerio Fiscal, que pidió tres años de prisión, siendo absuelto en el juicio penal, celebrado un mes después, al apreciarse la eximente de actuación en legítima defensa".

Luego, otro caso: “(.,.) la Sentencia de la Corte de Casación italiana, de 5 de abril de 2012 (NGCC 2012, I, 836), ha resuelto un litigio relacionado con un archivo alojado en la web de un diario, en el que se recogía la antigua noticia del arresto por corrupción de un político, que después sería absuelto(...)en el caso de las noticias contenidas en archivos históricos de periódicos a los que se puede tener acceso por internet, debe reconocerse al sujeto concernido la posibilidad de contextualizar y actualizar la información, mediante su conexión con otras, posteriormente publicadas, en particular la relativa a su absolución. Afirma, así que, si bien la información dada era verdadera al tiempo de la publicación originaria de la noticia, su posterior alojamiento en un archivo de carácter histórico ha de ser realizada, de tal modo que la misma siga conservando su veracidad y exactitud, tanto en beneficio del sujeto afectado, como en provecho del público destinario de ella".

Además, mencionando a Italia, se tiene: “(...) la Sentencia de la Corte de Casación, de 9 de abril de 1998 (FI 1998, I, 1834), ha admitido, explícitamente, el derecho al olvido. Más recientemente, la sentencia de la misma Corte, de 5 de abril de 2012 (NGCC 2012, I, 836), afirma que, si el interés público a la libertad de información limita el derecho a la intimidad, no obstante, al sujeto concernido, en aras al libre desarrollo de su personalidad, se le reconoce un derecho al olvido, esto es, a que no sean posteriormente divulgadas noticias que, por el transcurso del tiempo, resulten ya olvidadas o ignoradas para la generalidad de las personas. Ello, siempre que no exista un interés público a su actual consentimiento, por razones de carácter histórico, didáctico o cultural, o, más en general, porque persista un interés social en dicho conocimiento".

Es de señalar también de Italia: “(...) el Tribunal de Roma, el 15 de mayo de 1995 ('Dir. Informática', 1996, 422), en el que se afirmó que la nueva publicación, después de treinta años, de un hecho delictivo, con fines promocionales, constituye una difamación y obliga a la sociedad editora del periódico a resarcir el daño moral ocasionado, al tratarse de una información carente de interés público. En el caso litigioso, un periódico había 
reproducido una antigua página del 6 de diciembre de 1961, en la que se encontraba una noticia relacionada con un concurso semanal. Sin embargo, en dicha página aparecía, además, otra antigua noticia, relativa a una confesión de homicidio con el nombre y la fotografía del reo, el cual, tras haberse beneficiado de una reducción de condena y de una medida de gracia del Presidente de la República, se había reinsertado plenamente en la sociedad, tanto, desde el punto de vista personal y afectivo, como profesional. Al volverse a publicar la antigua noticia, su protagonista perdió su trabajo y la confianza de las personas que lo rodeaban".

Así también, en Francia es de verse: “(...)la sentencia del TPI de Namur, de 24 de noviembre de 1997 ('Legipresse', 1998, n. 154, III-123), afirma, así, que una persona condenada judicialmente tiene un real derecho al olvido, que se desprende del art. 8 CEDH y del art. 19 del Pacto Internacional de Derechos Civiles o Políticos de Nueva York, el cual debe ser considerado como aquél que permite a la persona no dedicada a una actividad pública exigir el secreto y la tranquilidad, sin los cuales el libre desarrollo de su personalidad quedaría coartado. Observa que el principio general ha de ser el del respeto del 'derecho al olvido' de la persona rehabilitada, a no ser que se trate de "redivulgar" hechos ya conocidos en la época en que tuvo lugar el proceso y de que exista un interés contemporáneo a esa 'redivulgación"”.

De Francia, es también de destacar: “(...)la Sentencia de la Corte de Apelación de Montpellier, de 8 de abril de 1997 ('Legipresse', 1997, n. 151, I-52), observa que el derecho al olvido no puede ser reconocido de manera absoluta, siendo el juez quien, en atención a las circunstancias del caso, debe determinar su alcance, teniendo en cuenta la gravedad de los hechos, el tiempo pasado desde su comisión y el esfuerzo de las personas condenadas, desde el momento en que, al haber purgado su pena, pueden oponerse legítimamente al recuerdo de su pasado, si dicho recuerdo no responde a ninguna necesidad de orden ético, histórico o científico".

Además, de Francia mencionar: “(...) la STGI de París, de 18 de diciembre de 1991 ('Legipresse', 1992, n. 8, III-1), en el que se apreció la ilicitud de un artículo aparecido en 'Paris Match' con el título 'Los ángeles del mal' (...) en el artículo se desvelaba el nombre y paradero actual de una mujer, que, después de haber cumplido su pena, se había alejado de su ciudad, trasladándose a Marruecos, donde dedicaba sus energías a cuidar a personas en un hospital. La mujer, en cuestión, después de la aparición del artículo se suicidó, para no decir la verdad sobre su vida anterior a su prometido. El Tribunal, con toda razón, consideró que se habían suministrado informaciones adicionales concernientes a su vida privada actual, las cuales no eran necesarias para la información del público".

Respecto de Alemania, es de referir: "La Sentencia del Tribunal Constitucional alemán, de 5 de junio de 1973 (BVerfGE 35, 202), afirma que, si bien, en principio, es lícito informar al público sobre ciertos hechos de la vida personal del criminal, en relación con los cuales ha sido declarado culpable, no obstante, el efecto de la irradiación de la protección constitucional de la personalidad impide que los medios de comunicación puedan extender, más allá de la información de hechos de actualidad y sin limitación de 
tiempo, el tratamiento de datos que conciernen a la persona de un criminal y a su esfera privada".

En España se aprecia que: “(...) en 1984 se publica una noticia en la que se afirma que una conocida gimnasta, que iba a participar en los próximos Juegos Olímpicos, sufre anorexia. Veintiséis años después, la protagonista de la noticia, casada y con hijos, se dirige al medio de comunicación con el fin que "de algún modo se advierta de que la información, aunque se creyera correcta en su momento, resultó ser falsa". La información en su día fue lícitamente publicada y no fue objeto de rectificación. Se refería a un personaje público, en la medida en que se trataba de una atleta olímpica, y abordaba un asunto que podía decirse de interés general, al poner el acento en los riesgos para la salud que podía entrañar una práctica deportiva en determinado nivel de exigencia. Nada de ello estaba en cuestión, solo que tras más de dos décadas, esa noticia seguía persiguiendo a la ex gimnasta al teclear su nombre en un buscador" (Mieres Mieres, 2014).

\section{Caso emblemático en España}

En principio, es de verse que aún no existe norma legal específica en España, respecto del derecho al olvido. Así tenemos, que ONTAÑ́́N RAMOS (2014) sostiene que la articulación del Derecho al Olvido, que no se encuentra expresamente regulado aún, surge con los perjuicios que causa el rastro de la información en Internet. Esto ha llevado a un largo conflicto entre la Agencia Española de Protección de Datos (AEPD) y Google, que, tras 11 años de batalla por reclamaciones y solicitudes de Tutela de ciudadanos, parece que ahora queda clarificado.

El Caso Google empieza cuando "Mario Costeja González, quien en el año 2010 acudió a la Agencia Española de Protección de Datos (AEPD) para formular un reclamo contra la editora del diario La Vanguardia, Google Spain y Google Inc. Según Costeja, introducir su nombre en el motor de búsqueda de Google arrojaba, entre otros, enlaces a dos páginas de La Vanguardia publicadas en enero y marzo de 1998, donde se anuncia la subasta de un inmueble suyo con motivo de la deuda que entonces tenía con la seguridad social. Costeja solicitó a la AEPD que La Vanguardia elimine esas páginas o las modifique de tal manera que ya no figure su nombre. Pedía, además, que Google no incluya entre los resultados referidos a su persona los enlaces a aquellas dos páginas. Argumentó que los anuncios de subasta por morosidad ya no tenían relevancia, pues su fin inicial, atraer compradores, había dejado de existir y, por añadidura, la deuda estaba saldada. La AEPD desestimó el reclamo de Costeja contra La Vanguardia, pero sí consideró correcto acoger el pedido en relación con Google Spain y Google Inc., por lo cual exigió a estas empresas que no asocien el nombre de Costeja a las dos páginas con el anuncio de la subasta. Google Spain y Google Inc., a su vez, recurrieron a la Audiencia Nacional para que se anule la resolución de la AEPD. Y, precisamente, la Audiencia Nacional dirige un pedido al Tribunal de Justicia de la Unión Europea para que se declare sobre el asunto interpretando la Directiva 95/46/CE, cuyo artículo 12 señala que una persona puede pedir que sus datos personales sean borrados una vez que ya no sean necesarios (...)" (Villena Saldaña, 2015, págs. 261-262). 
Seguidamente, respecto del caso Google, se revisa sucintamente lo reseñado por el CÁMARA PELLÓN (2014). En esta nueva y cambiante realidad, en la que parecen no existir leyes escritas, ha irrumpido la ya famosa Sentencia del Tribunal de Justicia de la Unión Europea de 13 mayo de 2104, en la que Google ha sido condenada a desvincular los resultados obtenidos en las búsquedas realizadas con los datos personales de un ciudadano español, que al teclear su nombre en el buscador, veía publicados y a disposición de los internautas, los anuncios de unas subastas celebradas frente a él por deudas con la Seguridad Social.

El posicionamiento del Tribunal de Luxemburgo, continúa CÁMARA PELLÓN (2014), posee una gran trascendencia y por ello mismo ha provocado un seguimiento mediático sin precedentes. En primer lugar, la Sentencia proclama que la actividad de hallar información con datos personales, ordenarla, almacenarla y ponerla a disposición de los internautas ostenta la consideración de tratamiento de datos personales a efectos legales. En segundo lugar, el Alto Tribunal atribuye la consideración de verdadero responsable de este tratamiento de datos al buscador, en la medida en que es él quien determina los fines y los medios de esta actividad. Finalmente, el Tribunal ampara el derecho del ciudadano a que los resultados obtenidos en la red que sean perjudiciales queden desvinculados de sus datos, lo que ha sido llamado generalmente como el derecho al olvido.

\section{El derecho al olvido en el Perú}

Mención especial merece el caso del abogado que en el 2015 demandó a Google que elimine cualquier información o noticia relacionada con la materia de sobreseimiento. Ello, en vista que en el 2009 fue denunciado porque la policía encontró su computadora llena de pornografía infantil. El demandante, que era profesor en la USMP, alega que en el 2012 se le declaró libre de toda culpa. Pero tenía un problema: cada vez que alguien googleaba su nombre, por supuesto, aparecía su caso en distintas webs periodísticas con pelos, señales y pedidos de detención incluidos. Producto de lo cual, Google Perú fue sancionado con una multa de más de 250 mil soles por una oficina del Ministerio de Justicia que responde al nombre de Dirección General de Protección de Datos Personales (DGPDP) (Sifuentes, 2016).

El presente caso, no ha tenido la trascendencia, ni la mediatez que obtuvo el caso emblemático de España referido. Sin embargo, lo que no deja a lugar a dudas, es que demuestra de manera contundente, el arribo del reconocimiento jurisprudencial del derecho fundamental al olvido en el Perú.

\section{1. ¿Un código del derecho al olvido?}

Sobre este acápite, a prioiri es pertinente dejar constancia que, a la fecha, a nivel del orbe, muy poco se ha legislado en predios de este nuevo derecho, al que denominaremos "en formación". 
Sin embargo, en vista que el derecho al olvido descansa basilarmente en el amplio escenario de la protección de datos y entendiendo que, a efectos de darle mayor oxigenación a su manejo y desarrollo, recientemente (a la fecha actualizado a enero de 2016) en España ha sido publicado en el Boletín Oficial del Estado (BOE) una selección y ordenación de la normatividad, denominándolo "Código de Derecho al Olvido".

Así es de verse, que el autor menciona en su nota al mismo, que hace las veces de parte introductoria: "(...) el término "derecho al olvido" (con independencia de su regulación europea en materia de protección de datos) cabe aceptarse como una referencia comprensible de diferentes acciones jurídicas concretas, destinadas a proteger a las personas, generalmente, en la red. Este código pretende hacer una recopilación de las principales normas referentes al llamado 'derecho al olvido', teniendo en cuenta los diferentes ámbitos en los que se puede plantear" (ABC Tecnología, 2014).

En ese sentido, se tiene que dicho importante documento (que importa más de 900 pp.) ciertamente no ostenta la categoría de Código, sino más bien, un compendio legislativo. Aunque sin duda, resulta ser de ineludible consulta y referencia al respecto. Debido a que, facilita su entendimiento y manejo del tema in comento.

Destacable el hecho que haya sido elaborado, a la luz de una suerte de mega bloque de constitucionalidad en dicha materia. Así tenemos, que a modo de mirada macro, en su contenido estructural contiene: i) Constitución española, ii) Normativa de protección de datos, iii) Sociedad de la información, y iv) Normativa conexa - Civil, Penal, Administración de justicia, Administraciones públicas, Menores, Sanitaria, Boletines oficiales, Indultos, Fuerzas y cuerpos de seguridad, Normativa penitenciaria, Telecomunicaciones, Consumidores y usuarios, Normativa tributaria, Seguridad social, y Publicación de sanciones de tráfico-.

A propósito, por su parte, la Red Iberoamericana de Protección de Datos (RIPD), aunque bastante más reducido, realizó un símil del referido Código, pero aplicado a la realidad jurídica peruana (y así también, para cada uno de los 23 Estados miembros restantes), denominándolo más propiamente como: Legislación. Que consta de: i) La Constitución Política: Incs. 5 y 6, del Art. $2^{\circ}$, Arts. $161^{\circ}$ y $162^{\circ}$ e Inc. 3., del Art. $200^{\circ}$, ii) Legislación General: Ley No 29733 de Protección de Datos Personales, Decreto Supremo Nº03-2013JUS, que aprueba el Reglamento de la Ley No 29733 y los Arts. 154, 156,157, 161-164, 207, del Código Penal, y iii) Legislación Sectorial: Ley No 26702 General del Sistema Financiero y del Sistema de Seguros y Orgánica de la Superintendencia de Banca y Seguros, Art. 8, de la Ley de Firmas y Certificados Digitales No 27269, Ley N 27309 que incorpora los delitos informáticos al Código Penal, Arts. 9 al 18, de la Ley que Regula las Centrales Privadas de Información de Riesgos y de Protección al Titular de la Información No $^{\circ} 27489$, Ley No 27806 de Transparencia y Acceso a la Información Pública, Decreto Supremo No 072-2003-PCM, que aprueba el Reglamento de la Ley No 27806, por los Arts. 1. y 3., de la Ley $\mathrm{N}^{\mathrm{0}} 28493$ que regula el uso del correo electrónico comercial no solicitado (SPAM), Decreto Supremo No 031-2005-MTC, por el que se aprueba el Reglamento de la Ley No 28493, Resolución Ministerial 111-2009 MTC/03, que salvaguarda derecho a la inviolabilidad y secreto de las telecomunicaciones y Protección Datos Personales y regula las acciones de supervisión y control a cargo del Ministerio de Transportes y 
Comunicaciones, Ley $\mathrm{N}^{\circ} 29499$, que establece la vigilancia electrónica personal, Ley $\mathrm{N}^{\mathrm{o}}$ 30024, por la que se crea el Registro Nacional de Historias Clínicas Electrónicas, Ley $\mathrm{N}^{\mathrm{o}}$ 30096, de Delitos informáticos, Directiva de Seguridad de la Información Administrada por los Bancos de Datos Personales, Ley No 30171, por la que se modifican los artículos 2, 3, 4, 5, 7, 8 y 10 de la Ley No 30096, de Delitos Informáticos, y Directiva sobre Tratamiento y Protección de Datos Personales en el Poder Judicial.

\section{A todo esto, ¿qué dice Google?}

Primero, Google puso a disposición de sus usuarios un formulario para que quienes decidieran ejercer este derecho, lo solicitaran sin muchas complicaciones. También creó un consejo asesor, a fin de contar con lineamientos generales que les permitieran equilibrar los diversos intereses que se concentran en este tema. A la quincena de julio de 2014, Google removió cerca de 91,000 resultados de búsqueda, principalmente de solicitudes de: Francia $(17,500)$, Alemania $(16,500)$, Reino Unido (12,000), España $(8,000)$, Italia $(7,500)$, y Países Bajos $(5,500)$. Y evalúa cada solicitud de manera individual, tomando en cuenta detalles como si el solicitante es una figura pública o si la información que se desea eliminar de los resultados fue hecha pública por la misma persona que lo solicita (Rosas, 2014).

Sin embargo, preocupa que la cifra señalada se haya elevado de manera exponencial. Así, CONTRERAS (2015) afirma que desde que en mayo de 2014 un Tribunal de Justicia de la Unión Europea decidiese que los europeos tenían el derecho de no salir en ciertos resultados de los buscadores en pro de que algunas informaciones pudiesen pasar al olvido, Google ha recibido casi un cuarto de millón de solicitudes pidiendo borrar resultados. (...) es curioso ver los datos que Google proporciona son en las direcciones que piden que se retire contenido, siendo Facebook el sitio con más URLs eliminadas, seguidas de una página de perfiles llamada profileengine.com, los grupos de Google (groups.google.com), YouTube y la red social de citas Badoo.

Dichas cifras ofrecen una lectura de la magnitud de lo que acontece en la referida materia, esto es una suerte de fuerza de la naturaleza, que apuntaría a ir en reflexivo como incontenible ascenso. Ello, obliga a Google a emprender acciones más que inmediatas, de muy amplia como de solvente plataforma de gestión de atención de solicitudes de derecho al olvido. Así, se entiende que pretendería encontrar un equilibrio entre el derecho de sus internautas o interés público y el derecho al olvido de los afectados. Tarea nada sencilla. Más aun, cuando, además, según ellos manifiestan, analizan las solicitudes caso por caso.

A su vez, es de resaltar que: "A pesar que en un comienzo se había negado a esta modalidad, Google finalmente aceptó eliminar algunos resultados de las búsquedas que se realicen en su buscador, además de su dominio '.com', en lo que era uno de los puntos de discusión por el 'Derecho al Olvido' y que le había hecho valer a la compañía de Mountain View una disputa con la Commission Nationale de I'informatique et des libertes (CNIL) en Francia y con el Tribunal de Justicia de la Unión Europea. Hasta hace un tiempo, la empresa eliminaba los links de los buscadores locales de los países europeos, pero no hacía 
lo mismo en su red internacional, argumentando que el tráfico que se obtenía desde allí hacia los sitios del 'Viejo Continente' era ínfimo" (Muñoz, 2016).

\section{3. ¿Derecho al olvido o sólo contra Google?}

Comúnmente se entiende, que el buscador por excelencia y hasta monopólico y único resulta ser el en apariencia, omnipresente Google en el orbe. Nada más alejado de ser cierto. Sin embargo, es de referir a KELION (2013), quien señala que en un momento Google fue el mejor motor de búsquedas del mercado, hoy esa afirmación es discutible dice STERLING de acuerdo al mismo KELION, un experto en tecnología que escribe en una web especializada. Aun así, la fortaleza de la marca, junto con la estrategia agresiva de Google en el mundo del móvil, han afianzado su liderazgo en casi todos los mercados de cara al futuro, añade STERLING. Nada es definitivo, pero es difícil imaginar otro competidor -fuera de Asia o Rusia- que vaya a ganar porcentajes significativos del mercado de búsquedas. Se señala ello, en razón a que, entre los principales candidatos a destronarlo, tenemos, continua KELION:

13.1. Bing. - El servicio de Microsoft es el principal competidor de Google y sus usuarios residen en Estados Unidos.

13.2. Llande. - El buscador más popular en Rusia tiene además versiones en inglés, turco y ucraniano.

13.3. Blippex. - La mayoría de los buscadores basan sus rankings de resultados en el análisis de palabras y vínculos en una página. Blippex por el contrario los ordena de acuerdo a su ranking Dwell, que mide la cantidad de tiempo que un usuario permanece en una página una vez que han hecho click en ella. Cuanto más tiempo permanezcan, más importante es la página para el buscador.

13.4. Wolfram Alpha. - Este buscador se describe a sí mismo como un "motor computacional de conocimiento" y estrictamente hablando no es un buscador, aunque la gente lo use para buscar información de terceros.

13.5. Blekko. - La característica única de Blekko son sus "slashtags", una herramienta para que los usuarios filtren los resultados que quieren obtener.

13.6. Naver. - El motor de búsquedas más popular de Corea del Sur data de 1999, año en que fue creado por un grupo de antiguos trabajadores de Samsung. Las búsquedas dan como resultado listas de hipervínculos inusualmente largas agrupadas de acuerdo a su lugar de proveniencia, blogs, redes sociales, anuncios, apps, libros o servicios de noticias.

13.7. Baidu. - Es de lejos el servicio más popular en China y deja a Google en cifras mínimas en el país asiático. La firma asegura que su punto fuerte es que no solo provee de vínculos sino también, en muchos casos, de la información que se busca. Esto puede incluir canciones o videos embebidos en los resultados e incluso apps interactivas. 
En consecuencia, de lo indicado se colige que, si bien es muy común que se solicite y en su caso, se accione legalmente contra Google, de manera digamos masiva, de manera alguna se constituye en el único buscador.

Por ende, es probable que, por ejemplo, que una vez conseguida la desvinculación de sus datos personales en el buscador Google, resulte que los mismos continúen figurando en otro buscador. Lo que complicaría, el ejercicio del derecho fundamental al olvido, por decir lo menos.

\section{4. ¿Y contra la Web más allá de la Web?}

Aparentemente, los buscadores o motores de búsqueda convencionales indicados en el acápite anterior, representan casi la totalidad de la información accesible vía la Red. Sin embargo, únicamente representa el $4 \%$ de la toda la información disponible (superficial web o web abierta). El $96 \%$ restante, está en la Deep Web, también denominada Internet Profunda. La misma que ofrece diversos niveles de información. Entonces, queda claro que accedemos a un porcentaje muy ínfimo de la información que figura en la Red.

Conocida también como invisible web, dark web o hidden web es todo aquel contenido que no forma parte del surface web. El contenido existente es privado, confidencial y muchas veces ilegal. Para entrar en la Deep Web se puede hacer por medio de la Red Tor y conociendo las url.onion. Entre lo que se puede encontrar en la Internet profunda tenemos: i)Mercado negro (armas, drogas...), ii) Servicios Hacking, iii) Piratería, iv) Contratación de sicarios, asesinos, espías..., v) Tráfico de órganos, animales, personas, vi) Porno ilegal, principalmente (Morales, 2014).

El motivo por el que abordo el tema de la Deep Web, en el desarrollo del derecho fundamental al olvido, radica en que se señala que la Deep Web contiene información no indexada, es decir, información que no figura en los buscadores o motores de búsqueda como Google, por ejemplo. Sin embargo, ello no necesariamente sería cierto, en tanto que existe información perteneciente a datos personales que figura en la Deep web. Consecuentemente, si tomamos en cuenta que no bastaría con solicitar y eventualmente conseguir desindexar datos personales, a la luz del derecho al olvido, no solo de Google, es decir, de la web superficial (lo cual, desde ya no resulta ser sencillo), imaginemos lo que significaría librar la batalla conducente a que lo propio se haga en la Deep Web.

En ese sentido, es de traer a colación a MIGLIORISI (2016, pág. 302) cuando indica que ha quedado demostrado en el presente que la libre expresión, la libertad de prensa y el derecho de acceso a la información en internet están ganando la batalla frente a quienes intentan cercenar su uso legítimo. Pero en el mismo sentido se encuentra quienes utilizas estos medios para el mal, para sembrar terror, tergiversar, potenciar el criminen organizado y avanzar hacia el lado oscuro de internet que como vimos son las profundidades de internet que en realidad en su mayoría se encuentran en la web superficial, la de uso doméstico. 


\section{Facebook lidera con mayor URL retiradas}

A primera impresión pareciera que quien encabezaría la lista sería Google. Sin embargo, es Facebook. Así tenemos que: "El Derecho al Olvido es un tema que en Europa se toma bien en serio, especialmente desde que la Unión Europea se pusiera muy estricta con el tema. Y ahora, Google ha actualizado su lista con los 10 sitios que más solicitudes reciben de parte de la gente, con Facebook a la cabeza del grupo. En total, estos 10 sitios suman un 9\% del total de los resultados que se solicita eliminar: 1. Facebook (10220 URLs quitadas), 2. ProfileEngine.com (7986), 3. Groups.Google.com (6764), 4. YouTube (5364), 5. Badoo (4428), 6. Plus.Google.com (4134), 7. Annuaire.118712.fr (3930), 8. Twitter (3879), 9. Wherevent.com (3465), y 10. 192.com (3083)" (Estrada, 2015).

Considero que los resultados indicados, obedecen principalmente a que en la actualidad Facebook se erige como la red social por antonomasia. Además, porque al utilizar la misma para dos funciones a la vez, esto es, como red social y red profesional (en lugar de utilizar para la segunda, LinkedIn), sobrecarga las posibilidades de solicitudes de desvinculación.

A propósito, cabe mencionar que también se aprecia otra figura muy peculiar, es decir, que se utiliza Facebook como red social y profesional, pero también, se usa LinkedIn como red profesional y social, con una marcada inclinación a la segunda. Ello refleja, que aparentemente no se entiende bien la naturaleza de la función de Facebook y LinkedIn. En esa línea, es de traer a colación lo expresado por Bill Gates (Gestión, 2016) cuando al respecto recientemente aseveró: "Si podemos hacer que LinkedIn sea tan apreciado como Facebook lo es en el mundo social, eso representaría una gran creación de valor y eso sucederá en el transcurso de algunos años".

\section{Dificultades del derecho al olvido}

Luego del recorrido de esta entrega, se es consciente de las diversas vicisitudes y limitaciones que le toca afrontar al derecho al olvido. En un derecho que si bien es cierto genera ciertos consensos, no aterriza aun en señeros derroteros en dicho sentido y a escala mundial.

En ese sentido, CANO (s.f.) acota que el derecho al olvido no está incluido en la Unión Europea y según Touriño ha nacido muerto. No obstante, las plataformas de Internet habilitan recursos para retirar contenidos con el objetivo de garantizar la seguridad y fiabilidad del usuario. Las redes sociales han tomado conciencia de que si no son rápidas y no ponen herramientas a disposición del usuario perderán la confianza y la fiabilidad de estos. De hecho, las opciones de reporte de abuso que ofertan son rápidas y efectivas. No obstante, la falsa sensación de aparente impunidad al malhechor, el desconocimiento por parte de la víctima y la falta de preparación del Derecho para hacer frente a las nuevas modalidades de infracciones, provocan inseguridad a los usuarios del espacio digital.

Cabe destacar que, si bien es de saludar el reconocimiento al derecho al olvido, las condiciones de su convivencia resultan ser nada pacíficas como preocupantes. Al respecto, 
es de verse que "el derecho al olvido en Internet tiene en los medios de comunicación online su más conflictivo escenario al ofrecer una aparentemente insalvable colisión entre el derecho a la protección de datos y la manifestación prototípica de la libertad de expresión y el derecho a la información" (Rallo, 2012).

Por otro lado, se tiene lo afirmado por el Secretario General adjunto del Consejo de Europa, cuando respecto del derecho al olvido reflexiona que "el aumento de la capacidad de almacenamiento y de tratamiento permite que la información sobre una persona circule por Internet, aunque ya no sea válida. Esto hace obsoletos los principios actuales de exactitud y proporcionalidad de los datos. Un nuevo derecho al olvido o a la eliminación automática de los datos permitiría que las personas tomaran control sobre el uso de sus datos personales" (De Terwagne, 2012, pág. 61).

A lo mencionado, habría que agregarle que una vez retirada la información agraviante, de manera preocupante, dicha información si podría ser encontrada en la Red. En ese sentido: "Si un hacker puede encontrar con facilidad 30 o 40 por ciento de los nombres de personas que aparecen en artículos retirados de las listas, ¿tiene sentido retirarlos?" (Scott, 2016).

Pero, si con lo mencionado no bastase, existe una modalidad por la cual, se sobrecarga indebidamente la Red con información de terceras personas, la misma que se vende de manera ilegal como indiscriminada. Así tenemos, que "en España, siete de cada 10 móviles tienen instalado WhatsApp. Así, el servicio de mensajería entrará de lleno en las técnicas de recogida y tratamiento masivo de información que encuentra el jugoso mercado de la publicidad digital. Sólo el año pasado este sector movió en España 1.288 millones de euros con un incremento del $21 \%$ con respecto a 2014, según un informe realizado por la consultora $P w C$. Se trata de un aumento desconocido en otros soportes tradicionales que sitúa al entorno digital como segundo receptor en volumen de inversión publicitaria, sólo por detrás de la televisión (...)"Cuando compartimos información haciendo un me gusta en las redes lo hacemos de forma voluntaria, generando mucha inteligencia: gustos, aficiones, ideología política, pautas culturales.... Todo eso se analiza, procesa y comercializa a anunciantes que buscan un público particular(...)" (Martínez \& Urrutia, 2016).

Entonces, queda claro, además, que el riesgo que la Red ofrezca información personal, la misma que no se desee que continúe siendo visible por los motores de búsqueda, se incrementaría en gran medida. Más aún si se considera que eventualmente dicha información, no solo sería vendida para fines comerciales.

\section{Problemas para unos, oportunidades para otros}

Es bien sabido, que este nuevo derecho ha habilitado un boom de oportunidades para ofrecer asesoría legal, para quienes buscan que, en virtud del derecho al olvido, sus derechos no sean vulnerados. Y ahí los tenemos, felizmente apostados cual Cyborgs o Terminators, venidos del futuro para salvar a quien lo requiera, de eso que también en no pocos casos, atormenta y casi destruye, esto es, alguna parte injusta, inexacta o desactualizada del pasado (a propósito, en el marco del presente estudio y a juzgar de ese 
perenne aspecto tan negativo que la Internet nos ha regalado, hace sopesar en unos, en que si tal vez, estuvimos mejor con el Capitán América).

En consecuencia y se entiende que la realidad así lo requiere, por ejemplo, en España, donde actualmente se experimenta la mayor movida al respecto, diversas empresas publicitan sus servicios en línea, Así tenemos entre otros: i) Tuabogadodefensor.com, ii) Navascusi.com, iii) Eliminalia.com, iv) Abanlex.com, v) Audea.com, vi) Openley.es, y vii) Borrame.es.

\section{Derecho al olvido en personas morales}

Ante todo, en el caso de las personas jurídicas (también denominadas, morales), conviene precisar que también son poseedoras de derechos fundamentales, tal como lo establece el Tribunal Constitucional peruano, en el Fundamento 4., de la Sentencia del Exp. № $00605-$ 2008-PA/TC, que juridiza: "Como premisa debe considerarse que las personas jurídicas pueden ser titulares de derechos fundamentales; sin embargo, ello no significa que dicha titularidad pueda predicarse de manera general respecto a todos los derechos, ya que ello estará condicionado a que así lo permita la naturaleza del bien protegido por el derecho en cuestión (...)".

Así también, como segundo punto, amerita indicar los derechos fundamentales que las personas morales. Así tenemos, que el Fundamento 14., de la Sentencia del EXP. N $4972-$ 2006-PA/TC, el Tribunal Constitucional peruano enseña: “(...) aun cuando no se pretende ensayar aquí una enumeración taxativa de los derechos que puedan resultar compatibles con la naturaleza o estatus de las personas jurídicas, cabe admitirse, entre otros, y desde una perspectiva simplemente enunciativa, los siguientes: a) El derecho a la igualdad ante la ley (Artículos 2, incisos 2, 60,63), b) Las libertades de información, opinión, expresión y difusión del pensamiento. El derecho a fundar medios de comunicación (Artículo 2, inciso 4), c) El derecho de acceso a la información pública (Artículo 2, inciso 5), d) El derecho al secreto bancario y la reserva tributaria (Artículo 2, inciso 5, párrafo segundo), e) El derecho a la autodeterminación informativa (Artículo 2, inciso 6), f) El derecho a la buena reputación (Artículo 2, inciso 7), g) La libertad de creación intelectual, artística, técnica y científica (Artículo 2, inciso 8), h) La inviolabilidad de domicilio (Artículo 2, inciso 9), i) El secreto e inviolabilidad de las comunicaciones y documentos privados (Artículo 2, inciso 10), j) La libertad de residencia (Artículo 2, inciso 11), k) El derecho de reunión (Artículo 2, inciso 12), l) El derecho de asociación (Artículo 2, inciso 13), m) La libertad de contratación (Artículo 2, inciso 14), n) La libertad de trabajo (Artículo 2, inciso 15, y Artículo 59), o) El derecho de propiedad (Artículo 2, inciso 16), p) El derecho a la participación en la vida de la nación (Artículo 2, inciso 17), q) El derecho de petición (Artículo 2, inciso 20), r) El derecho a la nacionalidad (Artículo 2, inciso 21), s) El derecho a la inafectación de todo impuesto que afecte bienes, actividades o servicios propios en el caso de las universidades, institutos superiores y demás centros educativos (Artículo 19), t) La libertad de iniciativa privada (Artículo 58), u) La libertad de empresa, comercio e industria (Artículo 59), v) La libre competencia (Artículo 61), w) La prohibición de 
confiscatoriedad tributaria (Artículo 74), x) El derecho al debido proceso y a la tutela jurisdiccional (Artículo 139 , inciso 3)”.

De lo descrito, se colige que es perfectamente posible que por ejemplo, una persona jurídica vea vulnerados sus derechos fundamentales (a la autodeterminación informativa y a la buena reputación), al tomar conocimiento que una noticia de hace una década en la que se le sancionó por haber atentado al derecho a la salud de los consumidores o estafa y que en ese mismo año cumplió con la sanción y subsanó debidamente las observaciones (más aun, en el caso que se haya demostrado en instancia final y definitiva, la falsedad del derecho supuestamente atentado), y que sin embargo a la fecha continúe figurando en los buscadores de internet. Ante lo cual, como persona jurídica (esto es, su representante legal), podría invocar la tutela procesal efectiva de su derecho fundamental al olvido.

\section{Conclusiones}

El derecho al olvido pertenece indudablemente al siglo XXI, aunque no solo a la presente generación, como producto de la multiplicidad de fuentes o facilidad de poder publicar información en las mismas, que nos regala los nuevos tiempos no solo de la era digital. Digamos que su arribo obedece a una suerte de pase de factura, por lo que la naturaleza misma que la Red comporta, esto es, la conversión de la memoria física, impresa o tradicional de la información, a la memoria en línea o virtual, a escala máxima, total como cuasi eterna.

Considerando que, el avance y desarrollo de la tecnología no puede significar únicamente elementos positivos o beneficiosos, luego de la creación de la internet allá en los años sesenta; era previsible la aparición del derecho fundamental al olvido luego de su vulneración sistemática y a nivel del orbe. Lo que, si resulta curioso, es que este tipo de menoscabo recién empiece a causar estragos en los internautas, luego de casi seis décadas. Retraso que deviene ciertamente en inquietante, por decir lo menos.

Se experimenta una transición del derecho al olvido, aunque existen ciertos avances, sobre todo en Europa (principalmente España), donde son basilarmente en predios de jurisprudencia y doctrina. Ergo, es de saludar que actualmente sea materia de discusión y arduos debates.

El reconocimiento al derecho al olvido, se encuentra destinado a salvaguardar los derechos on line de las personas físicas. Ello no tendría por qué excluir a las personas morales o jurídicas.

El derecho al olvido se encuentra en franco proceso de formación. Por lo que amerita la participación de los actores a efectos de lograr su pronto desarrollo y positivización en la legislación peruana. El mismo no debe ser entendido como absoluto, ya que enarbolar banderas de la absolutez en la defensa del derecho al olvido, no constituye un derrotero a seguir, en tanto que lo que debe procurarse y plasmarse en más bien un equilibrio de convivencia entre derechos que colisionan en no pocas oportunidades y que se deben más bien, armonizar. Lo que requerirá, además, de cantidades sostenidas como industriales de 
ponderación y razonabilidad, a efectos de salvaguardar los derechos de las personas naturales o físicas y por qué no decirlo, de las personas morales o jurídicas, también.

La problemática que el derecho al olvido reviste una suerte de paradoja. En razón a que, a expensas de los derechos de los perjudicados, la información personal on line continúa beneficiando a la web, en lugar de ser siempre en beneficio de las personas. Consecuentemente, no siendo Google el único buscador, es probable que, por ejemplo, que una vez conseguida la desvinculación de sus datos personales en el buscador Google, resulte que los mismos continúen figurando en otro buscador. Lo que complicaría, el ejercicio del derecho fundamental al olvido, por decir lo menos. Entonces, queda claro, además, que el riesgo que la Red ofrezca información personal, la misma que no se desee que continúe siendo visible por los motores de búsqueda, se incrementaría en gran medida.

Así también, que, entre el interés general de carácter histórico y el derecho al olvido, prevalece el primero, en tanto dicho interés persista al momento de la supuesta vulneración del segundo de los nombrados.

A propósito de la necesidad del saludable reconocimiento del derecho fundamental al olvido, consideramos pertinente, hacer mención que parece ser producto o estrago de la tercera Ola (correspondiente al predominio de la información y desarrollo tecnológico), debido a que, le estaría pasando factura a estos nuevos tiempos correspondientes a la cuarta Ola (que se identifica basilarmente, con la inteligencia artificial y la interface entre nanotecnología y la biología sintética). Digamos, que se trata de un efecto negativo, en razón a que comprensiblemente, el superlativo avance o progreso la informática y tecnología, no solamente es poseedor de efectos positivos para la humanidad, como es el caso, de la vulneración del derecho fundamental al olvido.

Antes de concluir, preciso señalar que ad portas de cumplir siete décadas de la Declaración Universal de los Derechos Humanos, es de verse que la vigencia, desarrollo y estricta observancia por el pleno respeto de los derechos humanos, constituye un reto de agenda permanente, sobre todo, si toma en cuenta el paulatino reconocimiento de nuevos derechos fundamentales. Además, a propósito del tiempo transcurrido, podemos colegir que los avances respecto de los tópicos mencionados, no serían los más auspiciosos. Ello nos debe comprometer más que nunca con dicho objetivo.

\section{Sugerencias}

Se precisa la delimitación de la que denomino, eternización de la información en el mundo de la Red, a favor del derecho fundamental al olvido. Y ante el conflicto entre el derecho al olvido entre ambas, debiera ponderarse a favor de la salvaguarda de los derechos fundamentales de las primeras. Ello, en razón a la propia naturaleza de las personas naturales y jurídicas; ya que, en las naturales se hablaría, por ejemplo, del derecho fundamental a la intimidad, el mismo que resulta ser notoriamente preeminente al derecho fundamental a la imagen de las personas morales. Sobre todo, hogaño, los factores: información, capacitación, concientización y voluntad política, se constituyen en señeros 
hacia el derrotero de la garantización de la tutela de los derechos fundamentales en su conjunto y de manera integral.

Definitivamente como en todo, el avance de la tecnología trae consigo sus bemoles, queda por lo tanto armonizar los derechos fundamentales, de manera preferente al escenario de la vigencia y desarrollo del derecho al olvido de los datos personales que figuran en la Red. Queda pues, legislar y reglamentar el derecho fundamental al olvido, con el objeto de ampliar la protección de derechos humanos y de las libertades fundamentales.

Parafraseando a Jessy Ownes, acoto que siempre es positivo el diálogo, reflexión y análisis (doctrina), en razón a que en mérito de los cuales, se genera el avance y plasmación de la legislación. Así, mientras más caminemos en espacios de la academia, como el presente, por ejemplo, mejor afrontaremos los retos cada vez mayores, que presenta la Internet, como en el presente caso, el derecho fundamental al olvido.

Exhorto a la producción y debate doctrinario y del juzgar prudente o jurisprudencia, en tanto que el hecho que el derecho fundamental al olvido, aun no se encuentre reconocido de manera expresa, no implica de manera alguna que las diversas formas de jurisdicción, se encuentren impedidas de resolver o sentenciar las reclamaciones o demandas.

Propongo que las decisiones no solo de los magistrados, sirvan además de tutelar debidamente el derecho al olvido, para procurar que el caso o los casos no terminen siendo presa del efecto contrario, es decir, que al margen que dicho derecho sea acogido, la persona no termine siendo inmortalizada mediáticamente por medios de comunicación. Logrando con ello, que el imaginario popular no termine olvidando el caso, incluso por buen tiempo. De darse así, sería como que el derecho al recuerdo, le termine ganando la batalla al derecho al olvido. No en los mejores términos, por supuesto.

Finalmente, constituye un reto, además, que, a puestas de la celebración del bicentenario de la nuestra independencia, sea una oportunidad inmejorable para mostrarnos y demostrarnos como una sociedad justa, democrática (aunque en strictu sensu, se sabe que el ser humano es antidemocrático por naturaleza, en vista que se rige por los principios de jerarquía y territorialidad) y, sobre todo, madura. Por ende, sea pues, además, motivo para que en pleno siglo XXI, los derechos fundamentales de las personas naturales y jurídicas, como el derecho fundamental al olvido, sea no solo reconocido y reglamentado legislativamente, sino también, debidamente tutelado.

\section{Bibliografía}

ABC Tecnología. (04 de 11 de 2014). El "Código del Derecho al Olvido" ya está disponible en el BOE. $A B C$. Obtenido de http://www.abc.es/tecnologia/redes/20141104/abci-codigoderecho-olvido-201411041616.html

Agencia Española de protección de Datos. (s.f.). Derecho al Olvido. Obtenido de http://www.agpd.es/portalwebAGPD/CanalDelCiudadano/derecho_olvido/index-idesidphp.php 
Beamonte, D. V. (2014). Breves reflexiones sobre el llamado derecho al olvido. Actualidad jurídica iberoamericana(1), 29-34.

Cámara Pellón, B. (18 de Octubre de 2014). El "derecho al olvido" en Internet, ¿un derecho conquistado? Obtenido de Garrigues: http://www.garrigues.com/es_ES/noticia/elderecho-al-olvido-en-internet-un-derecho-conquistado

Cano, L. (s.f.). El derecho al olvido y a la intimidad en Internet. Obtenido de Portal Comunicación: http://www.portalcomunicacion.com/monograficos_det.asp?id=260

Contreras, M. (14 de Mayo de 2015). Google ha recibido casi 250,000 solicitudes de derecho al olvido en Europa. Obtenido de FayerWayer: https://www.fayerwayer.com/2015/05/google-recibe-250000-solicitudes-derecho-olvido/

De Terwagne, C. (2012). Privacidad en Internet y el derecho a ser olvidado / derecho al olvido. Revista de Internet, Derecho y Política(13), 53-66.

Educar. (24 de Agosto de 2016). Hablamos de... el derecho al olvido (en Google). Obtenido de https://www.educ.ar/noticias/131340/hablamos-de-el-derecho-al-olvido-en-google

Estrada, R. (25 de Noviembre de 2015). Google revela los sitios más afectados por el derecho al olvido. Obtenido de FayerWayer: https://www.fayerwayer.com/2015/11/google-revelalos-sitios-mas-afectados-por-el-derecho-al-olvido/

Gestión. (18 de Junio de 2016). Bill Gates: LinkedIn será el Facebook de los profesionales. Obtenido de Gestión: https://gestion.pe/tecnologia/bill-gates-linkedin-sera-facebookprofesionales-124431

Hernández, J. (2016). Derecho al olvido en internet: una aplicación práctica de los derechos Arco. Obtenido de http://www.bloguismo.com/derecho-al-olvido-internet-una-aplicacionpractica-los-derechos-arco/

International Federation of Library Associations and Institutitons. (s.f.). Fundamentos y antecedentes legislativos: El "derecho al olvido" en el contexto nacional y regional. Obtenido de https://www.ifla.org/files/assets/clm/statements/rtbf-background-es.pdf

Kelion, L. (19 de Julio de 2013). ¿Cómo se busca sin Google? BBC. Obtenido de http://www.bbc.com/mundo/noticias/2013/07/130718_alternativas_google_busqueda_ar

Martínez, V., \& Urrutia, C. (11 de Septiembre de 2016). Google y Facebook: Tu vida a la venta por 10 euros. El Mundo. Obtenido de http://www.elmundo.es/economia/2016/09/11/57d2d02122601d4a668b45d7.html

Mate Satué, L. C. (2016). ¿Qué es realmente el derecho al olvido? Revista de Derecho Civil, 3(2), 187-222.

Mieres Mieres, L. J. (2014). El derecho al olvido digital. Obtenido de Fundación Alternativas: http://www.fundacionalternativas.org/public/storage/laboratorio_documentos_archivos/e 0d97e985163d78a27d6d7c23366767a.pdf

Migliorisi, D. F. (2016). Internet Profunda. Buenos Aires: DFM.

Morales, J. (12 de Febrero de 2014). TOR y la Deep Web, "La internet que no conocemos". Obtenido de Prezi: https://prezi.com/lvlu3i7yx1uj/tor-y-la-deep-web-la-internet-que-noconocemos/

Muñoz, D. (11 de Febrero de 2016). Derecho al olvido aplicará en las búsquedas de Google.com en Europa. Obtenido de FayerWayer: https://www.fayerwayer.com/2016/02/derecho-alolvido-aplicara-en-las-busquedas-de-google-com-en-europa/

Ontañón Ramos, I. (20 de Julio de 2014). El Tribunal de Justicia Europeo respalda el Derecho al Olvido. Obtenido de Noticias Jurídicas: http://noticias.juridicas.com/conocimiento/articulos-doctrinales/4921-el-tribunal-dejusticia-europeo-respalda-el-derecho-al-olvido/

Pérez de Acha, G. (9 de Septiembre de 2015). Una panorámica sobre el derecho al olvido en la región. Obtenido de Derechos Digitales América Latina: 
https://www.derechosdigitales.org/9324/una-panoramica-sobre-la-discusion-en-torno-alderecho-al-olvido-en-la-region/

Rallo Lombarte, A. (2010). El derecho al olvido y su protección a partir de la protección de datos. Madrid.

Rallo, A. (2012). El derecho al olvido en el tiempo de internet: la experiencia española. Castellón.

Revoredo, A. (26 de Julio de 2016). El Derecho al olvido: ¿El Derecho a olvidar a los responsables de la fuente original de información? Obtenido de El Cristal Roto: http://elcristalroto.pe/sin-categoria/el-derecho-al-olvido-el-derecho-olvidar-losresponsables-de-la-fuente-original-de-informacion/

Rosas, I. (26 de Julio de 2014). Algunos conflictos del derecho al olvido. Obtenido de FayerWayer: https://www.fayerwayer.com/2014/07/algunos-conflictos-del-derecho-al-olvido/

Scott, M. (13 de Junio de 2016). Investigadores descubren falla en el 'derecho al olvido' europeo. The New York Times. Obtenido de https://www.nytimes.com/es/2016/06/13/investigadores-descubren-falla-en-el-derechoal-olvido-europeo/

Sifuentes, M. (1 de Julio de 2016). Traición y olvido, por Marco Sifuentes. El Comercio. Obtenido de https://elcomercio.pe/opinion/rincon-del-autor/traicion-olvido-marco-sifuentes-229911

Villena Saldaña, D. (2015). Derecho al olvido en Internet: Google y la doctrina europea. Contratexto(23), 259-269. 